\title{
Sinopse de Huberia DC. (Melastomataceae: Merianieae) ${ }^{1}$
}

\author{
JOSÉ FERNANDO A. BAUMGRATZ2
}

(recebido: 12 de fevereiro de 2003; aceito: 6 de março de 2004)

\begin{abstract}
Synopsis of Huberia DC. (Melastomataceae: Merianieae)). This paper is a synopsis of the genus Huberia which has been recently reviewed. It is a neotropical genus comprising 16 species that occur in the Brazilian Atlantic coast and in the Andean cordillera, from south Ecuador to northwest Peru. The author provides a description of the genus, a key, and nomenclatural types, synonymy, distribution, brief habitat descriptions, vernacular names, and a list specimens examined referring to each species. Taxonomic affinities of the species and systematic position of the genus are commented.
\end{abstract}

Key words - Huberia, Melastomataceae, neotropics, synopsis, taxonomy

RESUMO - (Sinopse de Huberia DC. (Melastomataceae: Merianieae)). Aborda-se a taxonomia de Huberia, sendo reconhecidas 16 espécies distribuídas de modo disjunto na costa brasileira e nos Andes, do sul do Equador ao noroeste do Peru. São fornecidos descrição e posição sistemática do gênero, chave analítica, e citação dos tipos nomenclaturais, sinonímia, comentários sobre afinidades taxonômicas, distribuição geográfica, breve descrição de hábitat, nomes vulgares e lista das coleções botânicas de cada espécie.

Palavras-chave - Huberia, Melastomataceae, neotrópico, sinopse, taxonomia

\section{Introdução}

Cogniaux (1891) quando elaborou a monografia sobre as Melastomataceae, abrangendo todas as espécies até então conhecidas, circunscreveu Huberia com nove espécies, sendo oito brasileiras e uma restrita ao norte do Peru. A inexistência de um trabalho recente com novas abordagens taxonômicas e uma chave analítica para identificar todas as espécies reconhecidas, foram fatores preponderantes para se desenvolver $o$ presente estudo. Com base em dados morfológicos e anatômicos e na análise dos exemplares-tipo, Huberia é reconhecido como um gênero tropical e subtropical, exclusivo do continente sul-americano, constituído de 16 espécies, sendo 12 brasileiras, três restritas ao Peru e uma ocorrendo no Equador e Peru. Dentre esses táxons, sete foram descritos recentemente (Baumgratz 1999, 2000a, b). Das dez espécies estabelecidas nos séculos passados, nove foram consideradas válidas e $H$. glabrata sinônimo de $H$. glazioviana; Huberia annulata (Vent.) DC. é sinônimo de Marumia annulata Triana e H. argentea (Vent.) DC., de Miconia squamulosa Triana.

Este trabalho objetiva contribuir para o conhecimento da diversidade das Melastomataceae, em

1. Parte da tese de doutorado desenvolvida na Universidade de São Paulo, SP, Brasil.

2. Instituto de Pesquisas Jardim Botânico do Rio de Janeiro, DIPEQ/PROTAXON, R. Pacheco Leão 915, 22460-030 Rio de Janeiro, RJ, Brasil. jbaumgra@jbrj.gov.br particular do gênero Huberia, assinalando características morfológicas diagnósticas, genéricas e específicas, descrição e posição sistemática do gênero, tipos nomenclaturais, sinonímia e comentários sobre afinidades taxonômicas, dados biogeográficos e especificidades de hábitats. Além disso, poderá auxiliar trabalhos de inventários florísticos que têm sido realizados na região neotropical, apresentando-se uma chave analítica para a identificação das espécies e uma lista das coleções estudadas, que representam amostras de referências nomenclaturalmente revisadas, para análises comparativas e outros estudos acerca desse gênero.

\section{Material e métodos}

Os dados obtidos resultam de revisão bibliográfica e análise das coleções disponíveis nos herbários citados ao longo do trabalho, cujas siglas seguem Holmgren et al. (1990), inclusive exemplares e fotografias de tipos. Expedições científicas foram realizadas para coleta de material botânico e obtenção de dados ecológicos e sobre as plantas. Amostras foliares, florais e frutíferas foram fixadas em álcool a 70\% e utilizadas na análise morfológica. O material foi herborizado segundo técnicas usuais e incorporado ao acervo do herbário RB. A terminologia utilizada baseia-se no IBGE (1992), para os tipos de hábito, em Radford et al. (1974), para características morfológicas, Hickey (1979), para o padrão de nervação foliar, Harrington \& Durrell (1957), para o tipo de indumento, Mentink \& Baas (1992), Uphof (1962) e Wurdack (1986), para os tipos de tricomas, e em Baumgratz (1985), para os tipos de frutos e sementes. Na interpretação morfológica das 
inflorescências, utilizaram-se os conceitos de Barroso et al. (1994), Briggs \& Johnson (1979) e Troll (1964, 1969), com modificações quando necessárias. Na diafanização de folhas, empregou-se normalmente a técnica de Strittmatter (1973), às vezes com variações usadas por Johansen (1940), Marquete (1979) e Klucking (1989). A caracterização da vegetação segue basicamente as propostas do IBGE (1992) e quando da disponibilidade de dados regionais mais precisos, Brade (1956), Giulietti et al. (1987) e Weberbauer (1945). Elaborou-se uma chave analítica para a identificação das espécies. Na confecção das ilustrações, utilizou-se microscópio estereoscópico (Carl Zeiss Stemi SV 6), com câmara clara, em diferentes escalas de aumento. Adotou-se o sistema de classificação proposto por Cogniaux $(1886,1891)$ para as Melastomataceae e os conceitos de Prance (1989, 1990, 1994a, b) para as províncias florísticas ou fitocórias citadas para cada espécie.

\section{Resultados e Discussão}

Huberia DC., Prodr. 3: 167. 1828, p.p.

Lectótipo, aqui designado: Huberia ovalifolia DC., Prodr. 3: 167. 1828.

Árvores ou arvoretas, às vezes, arbustos. Indumento denso a esparsamente furfuráceo; tricomas glandulares, estrelados e/ou dendríticos, às vezes, também viloso- ou ciliado-glanduloso, geralmente obscurecido por substância viscosa em material seco, caducos ou não. Ramos decussados, tetragonais a cilíndricos. Folhas decussadas, pecioladas, sem estípulas; lâmina membranácea a coriácea, elíptica, ovada, obovada ou oblonga, base aguda a subarredondada, ápice acuminado a arredondado, margem inteira a serrada; 3 nervuras acródromas, basais ou suprabasais; domácias peciolares ou laminares, axilar-primárias, ou ausentes. Inflorescências terminais, às vezes pseudo-axilares, em pleiotirsóides, tirsóides, cimóides, cimas umbeliformes, metabotrióides, botrióides ou tríades, raro mônades; brácteas e profilos geralmente caducos. Flores 4(5)meras, pediceladas; hipanto tubuloso, persistente no fruto, constrito no ápice, costado ou anguloso, às vezes alado; cálice gamossépalo, persistente no fruto, lacínias triangulares, subuladas ou reduzidas a lobos oblongos ou ovados; pétalas ovadas a obovadas, ápice acuminado a arredondado, glabras; estames 8(-10), férteis (4-7-)8, desiguais ou de dois tamanhos, maiores antessépalos, menores ante-pétalos; anteras triangulares ou oblongas, subuladas, poro ventral, tecas planas a onduladas, conectivo com apêndice dorsal; estaminódios geralmente ausentes, raro 1-4, desiguais em tamanho, ante-pétalos, filiformes; ovário mediano, livre no interior do hipanto geralmente na maior parte de seu comprimento, (3)4-locular, glabro, placentação axilar; estilete filiforme-subulado, curvo no ápice a sigmóide, glabro; estigma geralmente punctiforme, às vezes capitado. Frutos do tipo ruptídio, (3)4-valvares, urceolados, polispérmicos, hipanto costado, anguloso ou alado, base ventricosa; sementes aladas, planas, côncavas ou naviculares, filiformes, lineares, elípticas, obovadas ou ovadas, granulado-estriadas.

O epíteto Huberia é homenagem ao naturalista Francis Huber, por seus estudos sobre abelhas e germinação de sementes, e a seu filho, Peter Huber, entomólogo, dedicado às formigas (De Candolle 1828).

O gênero é circunscrito, principalmente, pelo indumento furfuráceo-glanduloso, lâmina foliar com três nervuras acródromas, flores 4(5)-meras, hipanto tubuloso, com um só feixe vascular nas regiões intercostais, cálice gamossépalo, estames férteis, raro alternados com estaminódios, anteras com poro ventral, apêndice do conectivo dorsal, ovário mediano, livre no interior do hipanto geralmente na maior parte de seu comprimento, glabro, com lóculos ante-pétalos, frutos do tipo ruptídio, urceolados, com sementes aladas (figuras 1,2).

Huberia integra formações do complexo Floresta Atlântica e dos Andes e áreas de campo rupestre, restinga e enclaves florestais isolados no cerrado e caatinga, no território brasileiro. Assinala-se dois centros de diversidade genética para o grupo - um na costa brasileira, onde ocorre a maioria das espécies, principalmente na região Sudeste, e outro no sul do Equador e noroeste do Peru (figura 3).

Apesar das recentes propostas de classificação para as Melastomataceae mostrarem resultados ainda controvertidos (Clausing \& Renner 2001, Conti et al. 1996, Renner 1993), Huberia e gêneros afins têm sido mantidos na tribo Merianieae, estabelecida por Triana $(1865,1871)$, e caracterizada principalmente pelo hábito arbóreo ou arbustivo, frutos secos capsulares, flores grandes e estames com conectivo espessado no dorso, não prolongado abaixo das tecas, com apêndices geralmente dorsais, e sementes cuneadas, elípticas ou lineares a filiformes. Dos gêneros que integram essa tribo, Behuria Cham. é, provavelmente, o mais próximo de Huberia, principalmente pelo estame dorsalmente apendiculado e ovário 4-locular. Entretanto, difere deste pelas flores freqüentemente hexâmeras, ovário com ápice piloso, fruto do tipo velatídio e sementes, embora aladas, de forma subtriangular, achatadas lateralmente, com alas estreitas, consistentes, espessas e de textura 


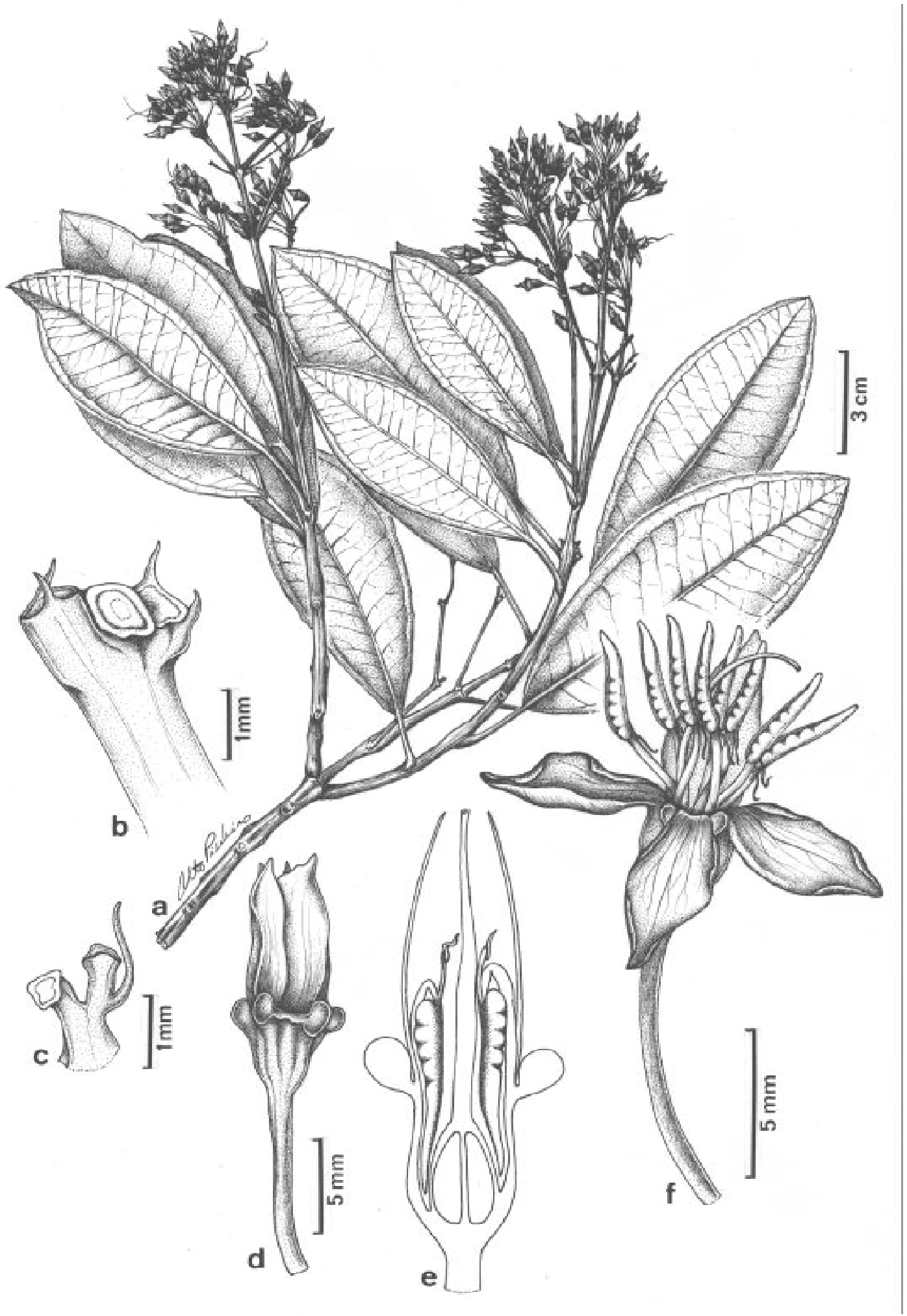

Figura 1. Huberia glazioviana. a. Ramo florido. b-c. Inserção de profilos e bráctea, respectivamente. d. Botão floral. e. Esquema da secção longitudinal do botão floral, evidenciando a disposição das peças florais e a adnação do ovário ao hipanto. f. Flor. (Baumgratz 630).

Figure 1. Huberia glazioviana. a. Flowering branch. b-c. Prophylls and bracts on inflorescence, respectively. d. Flower bud. e. Flower bud, showing the floral parts and partial adnation of the ovary to the hypanthium, longitudinal section. f. Flower.(Baumgratz 630). 


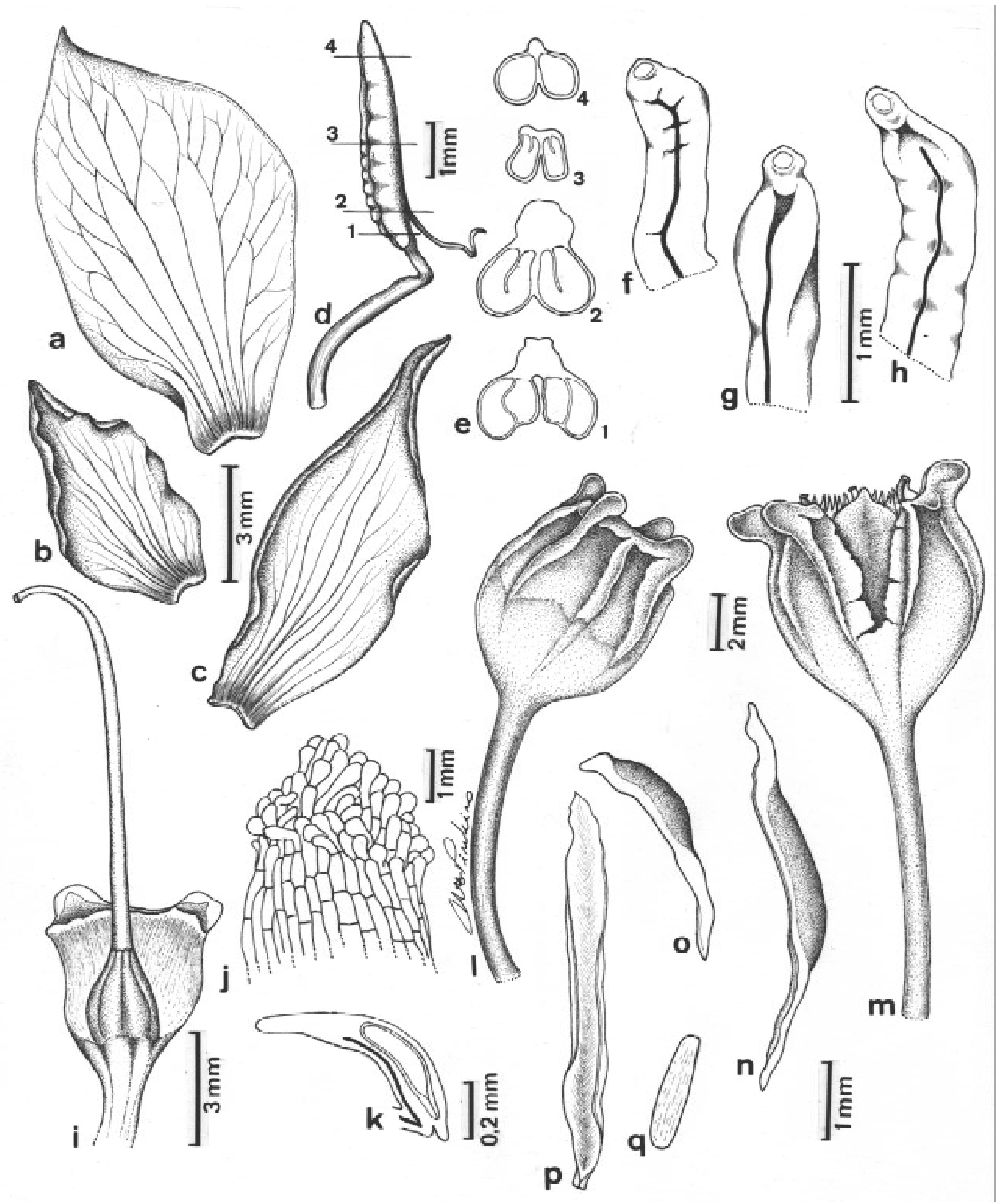

Figura 2. Huberia glazioviana. a-c. Pétalas: variação morfológica. d. Estame. e. Esquemas de secções transversais da antera, em diferentes níveis, evidenciando lóculos e septos. f-h. Ápice das anteras: variação morfológica e poro ventral. i. Gineceu. j. Detalhe do estigma papiloso. k. Óvulo. 1-m. Frutos maduros indeiscente e deiscente, respectivamente. n-p. Sementes: variação morfológica. q. Embrião. (Baumgratz 630).

Figure 2. Huberia glazioviana. a-c. Petals: morphological variation. d. Stamen. e. Anther at levels shown in Fig. 2d, illustrating loculi and septa, transverse sections. f-h. Apical anthers tube (morphological variation) and ventral pore. i. Gynoecium. j. Stigma. k. Ovule. 1-m. Mature fruit: indehiscent to dehiscent. n-p. Seeds: morphological variation. q. Embryo. (Baumgratz 630). 


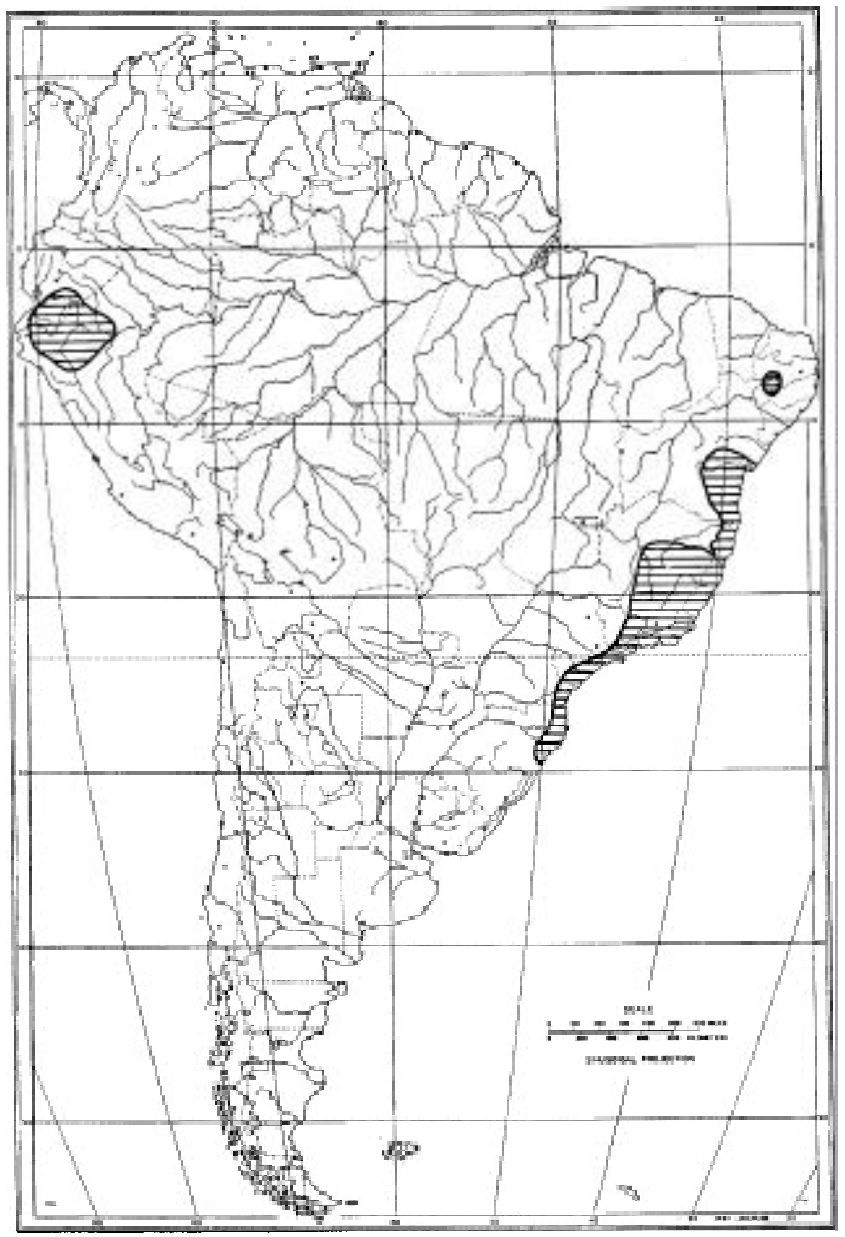

Figura 3. Distribuição geográfica de Huberia (Melastomataceae).

Figure 3. Geographic distribution of Huberia (Melastomataceae). esponjosa (Baumgratz 1985), além de sua ocorrência exclusiva no Sudeste do Brasil. Meriania Sw., que se aproxima mais de Behuria pelo tipo de fruto, distinguese pelas flores pentâmeras, apêndice estaminal ascendente, paralelo à antera na face dorsal, e sementes piramidais, nunca aladas.

Pelo tipo de semente alada, vários gêneros aproximam-se de Huberia, como Acanthella Hook. f., Benevidesia Cogn., Bisglaziovia Cogn., Calyptrella Naudin e Graffenrieda DC. Entretanto, diferem por várias particularidades na morfologia floral e frutífera (Cogniaux 1883-1888, Krasser 1893, Baumgratz 1985) - Graffenrieda tem apêndice estaminal basifixo, vertical, acicular e fruto do tipo velatídio; Calyptrella, cálice caliptriforme e fruto do tipo cápsula loculicida; Bisglaziovia, flores pentâmeras e fruto 5-valvar; Benevidesia, fruto do tipo cápsula loculicida e sementes subtriangulares, comprimidas lateralmente, com alas espessas; e Acanthella, fruto do tipo velatídio, com sementes largamente ovadas e rafe acentuadamente expandida na face ventral, formando uma sub-ala.

Os demais gêneros da tribo - Adelobotrys DC., Axinaea Ruiz \& Pav., Centronia D.Don, Dolichoura Brade, Merianthera Kuhlmann, Neblinanthera Wurdack, Ochthephilus Wurdack, Pachyloma DC., Phainantha Gleason e Tessmannianthus Markgraf não apresentam uma estreita relação com Huberia, principalmente por nítidas diferenças morfológicas de estruturas da flor, fruto e sementes.

\section{Chave analítica para identificação das espécies de Huberia}

1. Lâmina foliar coriácea, furfurácea, tricomas glandulares, estrelados e dendríticos; inflorescências multifloras, com mais de 140 flores H. glazioviana

1. Lâmina foliar membranácea, papirácea, subcartácea ou cartácea, às vezes subcoriácea, furfuráceoglandulosa, tricomas estrelados e dendríticos ausentes, ou face adaxial também esparsamente glanduloso-vilosa; inflorescências paucifloras, se multifloras com até 50 flores, raro flor solitária 2. Pedicelo floral 4-costado para o ápice; hipanto e cálice, inclusive no fruto, 4-alados; lacínias do cálice aladas H. semiserrata

2. Pedicelo floral, hipanto e cálice, inclusive no fruto, 8-angulosos ou 8-costados, nunca alados; lacínias do cálice nunca aladas

3. Flores 4(5)-meras, com estames férteis e estaminódios

H. staminodia

3. Flores sempre 4-meras, com todos os estames férteis

4. Lacínias do cálice em forma de lobos oblongos, ovados ou oblatos, às vezes sub-triangulares

5. Lâmina foliar com 1/3-inferior da margem inteiro, $2 / 3$ superiores crenulados ou serrulados nervuras acródromas 1-8 mm suprabasais; lacínias do cálice 2-2,6 mm compr., com três feixes vasculares; estilete $8-13 \mathrm{~mm}$ compr.

5. Lâmina foliar geralmente com margem inteira, às vezes levemente ondulada ou crenulada, nervuras acródromas basais; lacínias do cálice 0,3-1,7 mm compr., com 7-15 feixes vasculares; estilete 14-35 mm compr. 
6. Lacínias do cálice 1,4-2,1 mm larg., oblatas, dorsalmente gibosas na região mediana, ápice amplamente arredondado, não subcilíndrico, com 11-15 feixes vasculares; pétalas com ápice arredondado ou arredondado-obtuso, às vezes obtuso-apiculado a arredondado-apiculado ou assimétrico, neste caso arredondado e agudo lateralmente.

H. ovalifolia

6. Lacínias do cálice 0,3-0,8 mm larg., oblongas, às vezes estreitamente ovadas, crassas, ápice subcilíndrico e arredondado, com 7(-9) feixes vasculares; pétalas com ápice agudo a acuminado, às vezes obtuso ou sub-arredondado.....

H. consimilis

4. Lacínias do cálice estreitamente triangulares

7. Hipanto, inclusive no fruto, acentuadamente costado, costelas espessas e crassas .... H. nettoana

7. Hipanto, inclusive no fruto, liso ou 4-8-anguloso e/ou 4-8-estriado

8. Folhas com nervuras acródromas suprabasais; frutos com hipanto liso, nem anguloso nem estriado H. triplinervis

8. Folhas com nervuras acródromas basais (também suprabasais em H. laurina); frutos com hipanto anguloso ou estriado, nunca liso

9. Frutos, incluindo pedicelo, hipanto e lacínias do cálice, 35-44 mm compr.

H. laurina

9. Frutos, incluindo pedicelo, hipanto e lacínias do cálice, até $26 \mathrm{~mm}$ compr.

10. Folhas sem domácias (exceto em H. parvifolia), as adultas com feixes vasculares envolvidos por bainha esclerenquimática; lacínias do cálice 3,2-8 mm compr.; pétalas com 7-12 feixes vasculares na base (Brasil)

11. Folhas com domácias laminares; profilos $0,8-7 \mathrm{~mm}$ compr.; pedicelo floral 2-3,5 mm compr.; hipanto 3,9-4,5 mm compr.; tecas planas; frutos com mais de 240 sementes.

11. Folhas sem domácias; profilos 0,3-2 mm compr.; pedicelo floral 5,5-13,5 mm compr.; hipanto 5-8 $\mathrm{mm}$ compr.; tecas acentuadamente onduladas; frutos com até 225 sementes

12. Lâmina foliar papirácea, base arredondada; inflorescência furfuráceo-glandulosa e esparsamente viloso-glandulosa; pedicelo floral tetragonal; pétalas com ápice atenuado-acuminado a cuspidado; frutos 4-angulosos para o ápice, com mais de 190 sementes (Minas Gerais)

H. piranii

12. Lâmina foliar membranácea, base geralmente aguda ou obtusa, às vezes subarredondada ou arredondada; inflorescência furfuráceo-glandulosa; pedicelo floral cilíndrico ou subcilíndrico; pétalas com ápice acuminado, agudo, obtuso ou retuso; frutos inconspicuamente 8-nervados ou, alternadamente, 4-angulosos e 4-nervados, com até 150 sementes (Bahia e Espírito Santo)

13. Lâmina foliar com nervuras acródromas laterais geralmente confluentes às margens na base, nervuras secundárias transversais 16-24; profilos 0,4-0,8 mm compr.; flores 33-40 mm compr.; estames desiguais em tamanho, 15-18 mm compr.; estilete 20-24 mm compr.; frutos 21-26 mm compr., com até 75 sementes (Bahia) H. carvalhoi

13. Lâmina foliar com nervuras acródromas laterais nunca confluentes às margens, nervuras secundárias transversais 11-13; profilos 1,2-2 mm compr.; flores $23-25 \mathrm{~mm}$ compr.; estames de dois tamanhos, 12-15 mm compr.; estilete 18-19 mm compr.; frutos (11-13)14-21 mm compr., com mais de 120 sementes (Espírito Santo) H. espiritosantensis

10. Folhas com domácias, as adultas com feixes vasculares desprovidos de bainha esclerenquimática; lacínias do cálice 1,1-2,5 mm compr.; pétalas com 5-6 feixes vasculares na base (Peru) 
14. Folhas com domácias peciolares, semelhantes a diminutas bolsas infladas, fendidas; profilos 1-2 mm compr.; lacínias do cálice 2,1-2,5 mm compr.; frutos 20-26 mm compr., com pedicelo de 11-15 mm compr.

H. peruviana

14. Folhas com domácias laminares; profilos $0,4-0,8 \mathrm{~mm}$ compr.; lacínias do cálice 1,1-1,9 mm compr.; frutos 11-17 mm compr., com pedicelo de 2,3-10 mm compr.

15. Pecíolo e face adaxial da lâmina foliar esparsamente vilosoglandulosos quando jovens, além de furfuráceo-glandulosos; pedicelo floral 9-11 mm compr;; hipanto 5,5-6,2 × 2,5-3 mm; lacínias do cálice 1,5-1,9 mm compr.; pétalas 12-14 × 4,5-5,8 mm, ápice agudo a obtuso-apiculado; anteras com tecas acentuadamente onduladas; estilete 14-16 mm compr. H. weberbaueriana

15. Pecíolo e lâmina foliar glanduloso-furfuráceos, não glandulosovilosos; pedicelo floral 5,5-6mm compr.; hipanto 3,8-4,5 $\times$ 1,8-2,1 mm; lacínias do cálice 1,1-1,3 mm compr.; pétalas 9,2-9,8 $\times 3,1-3,5 \mathrm{~mm}$, ápice acuminado; anteras com tecas planas a levemente onduladas; estilete 11-13 mm compr.

H. cogniauxii

1. Huberia carvalhoi Baumgratz, Brittonia 52(1): 25, figs. 1-3. 2000. Tipo: BRASIL: BAHIA: Nilo Peçanha, estrada Nilo Peçanha para Cairu, ca. $4 \mathrm{~km}$ após a bifurcação Cairu/Camamu, à beira da estrada no lado direito, 4-IV-1992, J.F.A. Baumgratz et al. 643 (holótipo $\mathrm{RB}$; isótipos ALCB, CEPEC, FLOR, HB, K, P, R, SPF, US).

Nome vulgar: mundururu.

Huberia carvalhoi assemelha-se a $H$. laurina pelas lacínias do cálice estreitamente triangulares, um caráter muito valorizado por Cogniaux $(1886,1891)$. Distingue-se pelo indumento viloso-glanduloso das gemas vegetativas, lâmina foliar membranácea, com ápice freqüentemente acuminado ou atenuadoacuminado, maior número de nervuras secundárias transversais (16-24), pedicelo floral cilíndrico e menor em comprimento $(7-11,5 \mathrm{~mm})$, pétalas de ápice assimétrico, lateralmente acuminado, e frutos menores (21-26 ×5-6,5 mm). Também se aproxima de $H$. piranii e H. espiritosantensis pela forma das lacínias do cálice e tipo de indumento das gemas vegetativas, mas se diferencia de ambas pela lâmina foliar geralmente oblonga, estames subiguais em tamanho, maior comprimento do tubo apical das anteras $(0,8-1,7 \mathrm{~mm}) \mathrm{e}$ estilete (20-24 mm) e menor número de sementes (35-75) por fruto. Ainda difere de $H$. piranii pela base foliar geralmente aguda a obtusa, inflorescências normalmente com maior número de ramos (4-8) e pedicelo floral cilíndrico, e de H. espiritosantensis pelo maior número de nervuras secundárias transversais na lâmina foliar, maior comprimento das flores (33-40 mm), estames $(15-18 \mathrm{~mm})$ e frutos e maior largura das pétalas (6,5-11,5 mm).

Endêmica das planícies litorâneas dos municípios de Nilo Peçanha e Valença (BA), resultantes dos processos de acumulação fluvial e marinha (Radambrasil 1981), e situada na fitocória Centro Regional da Costa Atlântica, de alto grau de endemismo (Prance 1989, 1994a, b). Ocorre em capoeiras de solo arenoso, com piaçaval, e em restingas arbóreas, primárias ou perturbadas, em altitudes de 50 a $80 \mathrm{~m}$, com solo arenoso ou arenoso-argiloso, geralmente na borda ou em clareiras, onde possuem copa de formato oval, e também no interior da mata, com as copas estreitamente triangulares.

Material examinado: BRASIL: BAHIA: Nilo Peçanha, 11-VI-1973, T.S. Santos 2660 (CEPEC, US); 24-X-1984, L.A.M. Silva \& T.S. Santos 1767 (CEPEC, HRB); 22-IX-1988, L.A.M. Silva et al. 2578 (CEPEC); 5-XII-1986, P.A. Loizeau et al. 555 (CEPEC); Valença, 10-I-1982, A.M. Carvalho \& G.P. Lewis 1135 (CEPEC, HUEFS).

2. Huberia cogniauxii Baumgratz, Novon 9(2): 143, figs. 4-5. 1999. Tipo: PERU: Amazonas: Bongará, Laguna Pomacocha, ridge NE of lake, $77^{\circ} 52^{\prime} \mathrm{W}, 5^{\circ} 50^{\prime} \mathrm{S}$, elev. 2.450-3.350 m, 7-II-1985, B. Stein \& C. Todzia 2116 (holótipo MO; isótipos CAS, RB).

Nesta espécie, também se observam as gemas vegetativas e as regiões axilares adjacentes a estas 
com indumento viloso-glanduloso, cujos tricomas glandulares são semelhantes aos encontrados em $H$. weberbaueriana. Esses tricomas caem muito cedo e podem estar obscurecidos pela substância resinosa liberada pela planta durante o processo de herborização; restritos a determinadas estruturas jovens da planta, sugerem um meio de proteção à herbivoria. Em H. cogniauxii, as nervuras últimas marginais, embora muito tênues na face abaxial da lâmina foliar, são perceptíveis na face adaxial, desde a região basal até quase o ápice, e confluentes suprabasalmente às nervuras acródromas laterais, o que a diferencia das demais espécies peruanas.

Coletada em área próxima às das outras espécies peruanas, na região de Bongará, porém em altitudes de $2.450 \mathrm{~m}$ a $3.350 \mathrm{~m}$, a NE do lago Pomacocha, e caracterizada pela presença de floresta nebular, com trechos rochosos em clareiras abertas. Esta espécie integra as mesmas áreas fitogeográficas onde ocorrem $H$. peruviana, $H$. staminodia e $H$. weberbaueriana, nos Andes del Chamaya, na Ceja del Marañón (Weberbauer 1945) ou regiões de florestas úmidas das escarpas orientais (Young \& Léon 1993), e na fitocória Centro Regional Sub-montanhoso Andino Sul. Nessa localidade, a neblina é freqüente durante todo o ano e os indivíduos de H. cogniauxii são arvoretas com cerca de $3 \mathrm{~m}$ de altura. O caráter micro-endêmico desta espécie reforça a classificação dessa região peruana como um importante centro de endemismo (Prance 1990, 1994a, b), inclusive como um centro local de endemismo dentro do centro regional sub-montanhoso.

3. Huberia consimilis Baumgratz, Brittonia 52(1): 29, figs. 1, 4-5. 2000. Tipo: BRASIL: Rio DE JANEIRO: Macaé, Pico do Frade de Macaé, entre 800-1.000 m altitude, 18-II-1994, J.F.A. Baumgratz et al. 654 (holótipo RB; isótipos CEPEC, FLOR, GUA, HB, IPA, R, SPF).

Nome vulgar: mangue-do-mato (Rio de Janeiro).

Huberia consimilis é muito afim de $H$. ovalifolia, diferindo pela base foliar de aguda a obtusa, lacínias do cálice em forma de lobos oblongos, às vezes estreitamente ovadas, com 0,3-0,8 mm de largura e sete, raro oito ou nove, feixes vasculares principais, e pétalas com ápice acuminado a agudo. A diferença entre as formas das lacínias do cálice destas duas espécies é bem evidenciada nos frutos, onde os segmentos calicinais encontram-se mais eretos. Ainda pelas lacínias do cálice reduzidas, $H$. consimilis também se aproxima de $H$. glazioviana e $H$. minor, mas características morfológicas das folhas, inflorescências e flores diferem essas três espécies entre si.

Com distribuição geográfica restrita e disjunta ao longo da costa brasileira, ocorre em Pernambuco, Bahia e Rio de Janeiro. Nos dois primeiros estados é encontrada entre $800 \mathrm{~m}$ e $1.100 \mathrm{~m}$ de altitude, em Floresta Estacional Semidecidual ou Decidual, Floresta Ombrófila Densa e em topos de enclaves florestais isolados nos domínios da Caatinga e do Cerrado, como os brejos de altitude (Andrade-Lima 1960, 1966, 1970, Lyra 1984a, b, c), além de fragmentos de matas em regiões campestres, matas mesófitas ou matas de cipó em áreas de cerrado, na Bahia. No Rio de Janeiro, ocorre de $800 \mathrm{~m}$ até $1.800 \mathrm{~m}$ de altitude, desde mata de encosta até mata nebular, onde o solo apresenta-se mais raso e arenoso. Ocorre em três fitocórias: Centro Regional Nordeste do Brasil (Pernambuco e Bahia); Centro Regional Sul do Brasil (norte do Rio de Janeiro); e Centro Regional da Costa Atlântica (litoral-sul do Rio de Janeiro). Integra também áreas identificadas como refúgios florestais pleistocênicos (Prance 1989, 1994b), denominados de "Rio-Espírito Santo" e "Bahia". Huberia consimilis e H. ovalifolia constituem um par de espécies vicariantes - enquanto a primeira ocupa formações florestais montanhosas e interioranas, a segunda ocorre geralmente em formações de planícies litorâneas e matas dos tabuleiros e, às vezes, matas de altitude, porém próximas ao litoral.

Material examinado: BRASIL: BAHIA: Almadina, 10-III-1971, R.S. Pinheiro 1075 (CEPEC, IPA, NY, US); Barra da Estiva, 29-I-1974, R.M. Harley et al. 15642 (CEPEC, IPA, K, MO, NY, P, U); Mucugê, XII-1942, R.L. Fróes 19992 (IAN, NY); Maracás, 15-II-1979, T.S. Santos et al. 3458 (CEPEC, NY, US); Santa Teresinha, 6-VI-1984, L.R. Noblick et al. 3350 (CEPEC, HUEFS, MO, US); 14-XI-1986, L.P. Queiroz et al. 1055 (HUEFS). Pernambuco: Brejo da Madre de Deus, 5-II-1965, D. Andrade Lima 65-4304 (HRB, IPA). Rio de Janeiro: Macaé, 18-II-1994, J.F.A. Baumgratz et al. 657 (HB, R, RB); Rio de Janeiro, 8-II-1890, A.F.M. Glaziou 18229 (BR, G, K, R); Santa Maria Madalena, 25-VI-1987, H.C. Lima et al. 3008 (RB); 16-IX-1986, M. Leitman et al. 212 (RB); I-1933, J. Santos-Lima 113 (RB); 3-III-1935, J. Santos-Lima \& A.C. Brade s.n. (RB45545); 28-II-1934, J. SantosLima \& A.C. Brade 13212 (RB); 3-4-III-1935, J. Santos-Lima \& A.C. Brade 14251 (RB); Sem localidade, 15-III-1955, E. Pereira 1226 (RB).

4. Huberia espiritosantensis Baumgratz, Rodriguésia 50(76/77): 39, figs. 2-3. 2000 (1998) ["espiritosantensis”]. Tipo: BRASIL: EsPíRIto SANTo: Santa 
Teresa, Valsugana Velha, Estação Biológica de Santa Lúcia, ca. $19^{\circ} 58^{\prime}$ S, $40^{\circ} 32^{\prime} \mathrm{W}$, ca. 550-600 m alt., ao longo do rio Timbuí, base da cachoeira, margem direita, 13-III-1990, H.Q.B. Fernandes et al. 2906 (holótipo $\mathrm{RB}$; isótipos MBML, US).

Huberia espiritosantensis assemelha-se a $H$. laurina, $H$. piranii e $H$. carvalhoi (vide comentários desta última espécie). Pela forma das lacínias, H. espiritosantensis mostra também afinidade com $H$. nettoana, diferenciando-se pelas folhas com margem inteira, inflorescências com maior número de flores (21-33), menor comprimento das flores (23-25 mm), lacínias do cálice (4,5-6 mm), pétalas (9,5-17 mm), ovário (3-3,2 $\mathrm{mm})$ e fruto (11-21 mm), hipanto 8-anguloso e menor número de sementes (120-150) por fruto.

Endêmica da Estação Biológica de Santa Lúcia, município de Santa Teresa, Espírito Santo, integrada à fitocória Centro Regional da Costa Atlântica, ocorre em Floresta Ombrófila Densa montana, entre 550-600 m de altitude, em áreas de encosta ou margens de rios ou cachoeiras.

Material examinado: BRASIL: EsPíRITo SANTO: Santa Teresa, 11-IV-1988, H.Q.B. Fernandes 2450 (MBML, RB, US); 5-XII-1993, J.F.A. Baumgratz et al. 648 (RB).

5. Huberia glazioviana Cogn. in A. De Candolle \& C. De Candolle, Monogr. Phan. 7: 409. 1891. Tipo: BRASIL: RIO DE JANEIRO: Alto Macaé, 6-II-1888, A.F.M. Glaziou 16816 (holótipo BR; isótipos C, F, G, IAN, K, L, MO, NY, P, R, RB, UB; fotos do holótipo: F, GH, $\mathrm{MO}, \mathrm{NY}$; foto do isótipo $\mathrm{K}$ : RB; foto do isótipo IAN: $\mathrm{RB})$.

$=$ Huberia glabrata Cogn. in A. De Candolle \& C. De Candolle, Monogr. Phan. 7: 409. 1891. Tipo: BRASIL: Rio DE JANeiro: Alto Macaé, 2-XII-1887 (19-II-1888), A.F.M. Glaziou 16815 (holótipo BR; isótipos B n.v., C, F, G, IAN, K, L, P, R; fotos do isótipo B: F, GH, MO, $\mathrm{NY}$; foto do isótipo $\mathrm{K}$ : RB; foto do isótipo IAN: RB). Syn. nov.

Huberia ovalifolia e $H$. consimilis são as espécies mais afins de $H$. glazioviana (figuras 1,2 ), principalmente pelo hipanto anguloso, lacínias do cálice reduzidas a lobos curtos, crassos, dorsalmente gibosos e de ápice arredondado. Pela forma um pouco similar das lacínias do cálice, $H$. minor e H. peruviana também se aproximam dessa espécie, mas se distinguem pelas folhas geralmente menores $(3,2-7,6 \times 0,5-2,6 \mathrm{~cm}) \mathrm{e}$ membranáceas.
Restrita a Minas Gerais e Rio de Janeiro e situada na fitocória Centro Regional Sul do Brasil. Ocorre entre 700-1.500 m de altitude, em Florestas Ombrófila Densa montana e Estacional Semidecidual montana, e em formações secundárias, de natureza antrópica ou clareiras naturais, em encostas e bordas ou interior da mata, compondo ou não a estrutura de dossel ou como elementos emergentes em mata nebular. Quando em capoeiras ou locais sujeitos a queimadas periódicas, apresenta fuste e ramos curtos, sinuosos ou contorcidos, com casca grossa, nitidamente gretada ou fissurada. Assinala-se pela primeira vez a ocorrência de H. glazioviana em Minas Gerais, até então citada como endêmica do Rio de Janeiro (Pereira 1966), e numa nova localidade nesse estado, o Pico do Frade de Macaé.

Material examinado: BRASIL: Minas Gerais: Araponga (Carangola), 12-III-1989, L.S. Leoni \& A.M. Leoni s.n. (GFJP, SP244540, SPF66453); 1-XII-1993, J.F.A. Baumgratz et al. 647 (FLOR, SPF, RB); Mun. INDET.: Estouro, 14-II-1985, W.N. Vidal et al. 585 (VIC). Rio de JANEIRO: Macaé, 18-II-1994, J.F.A. Baumgratz et al. 655 (RB); Nova Friburgo, 19-IV-1989, H.Q.B. Fernandes et al. 2751 (MBML, RB); 19-IV-1989, H.C. Lima et al. 3530 (RB); 1-VI-1990, H.C. Lima et al. 3781 (RB); 25-V-1989, G. Martinelli et al. 13416 (RB); 17-21-VII-1989, M. Peron et al. 827 (RB); 8-VI-1989, J.F.A. Baumgratz et al. 439 (RB); 16-VIII-1990, J.F.A. Baumgratz et al. 456 (RB); 18-VIII-1990, J.F.A. Baumgratz et al. s.n. (RB397332); 24-II-1992, J.F.A. Baumgratz et al. 630, 630A-D (RB); 26-II-1992, J.F A. Baumgratz et al. 631, 631A-D (RB); 26-II-1992, J.F.A. Baumgratz et al. 632 (RB); 26-II-1992, J.F.A. Baumgratz et al. 633 (RB); 11-VIII-1992, J.F.A. Baumgratz et al. 646B (RB); Rio de Janeiro, 1-II-1891, Schwacke 7179 p.p. (RB).

6. Huberia laurina DC., Prodr. 3: 167. 1828. Tipo: In Brasilia. Melast. laurinum ser. mss., Herb. De Cand. Prodr. 7913, s. col., s.n. (holótipo G-DC n.v.; isótipo L; fotos do holótipo: F, GH, MO, NY).

Huberia laurina diferencia-se das espécies afins, $H$. carvalhoi, $H$. espiritosantensis e $H$. piranii, pelo maior comprimento do pedicelo floral (15-26 mm), ovário (5,2-6 $\mathrm{mm})$ e fruto (35-44 $\mathrm{mm})$, pétalas com ápice agudo e ausência de longos tricomas glandulares nas gemas vegetativas e na face adaxial da lâmina foliar. Em relação a $H$. piranii e $H$. espiritosantensis, assinalam-se, ainda, os estames subiguais em tamanho. De H. carvalhoi, a espécie mais próxima, difere também pela lâmina foliar cartácea, com ápice 
geralmente obtuso a arredondado, às vezes agudo, arredondado-apiculado ou obtuso-emarginado, nervuras acródromas laterais bem próximas às margens e menor número de nervuras secundárias (8-12), além do maior número de sementes (200-250) por fruto e pelos distintos locais de ocorrência, em Minas Gerais e São Paulo.

Ocorre na Serra do Cipó e em Ouro Preto, Minas Gerais, a 1.100-1.200 m de altitude, em capões e capoeiras. Uma única coleção (sem coletor $n$. 1098, $\mathrm{R})$, indica sua ocorrência em São Paulo, embora os dados sejam imprecisos. Considerando a falta de inventários florísticos em áreas pouco ou não exploradas, que H. laurina tem distribuição restrita e que espécies de Huberia são encontradas em formações florestais, pressupõe-se que, em São Paulo, esta espécie possa ocorrer em capões de mata em Cerrado ou Floresta Estacional Semidecidual, em regiões adjacentes a Minas Gerais.

Material examinado: BRASIL: MinAS GERAIS: Santa Luzia, 3-II-1934, A.J. Sampaio 6565 (BHMH, F, R, RB, SP); 1938, J.C. Badini \& M. Barreto 2078 (OUPR); 25-IV-1950, A.P. Duarte 2666 (NY, RB, US); Mun. indet., III-1839, P. Claussen 30 (BR); s.d., P. Claussen 50 (G, GH, RB), s.n. (F939716); Sem localidade, 1839, L. Riedel 12 (G, P); VIII-IV-1840, P. Claussen s.n. (K); 1841, C.F.P. Martius 942 (BM, BR, G, GH, K, L, MO, NY, US, WU; foto RB). SÃo PaUlo: sem localidade, s.d., s. col. 1098 (R).

7. Huberia minor Cogn. in A. De Candolle \& C. De Candolle, Monogr. Phan. 7: 409. 1891. Tipo: BRASIL: Rio de JANeiro: 19-II-1888, A.F.M. Glaziou 16818 (holótipo BR; isótipos B n.v., G, IAN, K, L, MO, NY,P, $\mathrm{R}, \mathrm{UC}$; fotos do isótipo $\mathrm{B}$ : F, GH, MO, NY; foto do isótipo IAN: $\mathrm{RB}$; foto do isótipo $\mathrm{K}: \mathrm{RB}$ ).

Huberia minor é próxima de $H$. parvifolia pela aparente semelhança das folhas, mas difere principalmente pelas nervuras acródromas suprabasais, desprovidas de domácias. Também se distingue pelas inflorescências em cimas corimbosas ou tríades, freqüientemente desprovidas de ramificações, às vezes com ramos inconspícuos, maior comprimento das flores (35-43 $\mathrm{mm})$, pedicelo floral $(13-22 \mathrm{~mm})$, hipanto (5-6 mm), ovário $(4,2-4,5 \mathrm{~mm})$ e fruto $(21-30 \mathrm{~mm})$, lacínias do cálice reduzidas a lobos ovados a subtriangulares, de menor comprimento (2-2,6 mm), e pelas anteras onduladas.

Endêmica do Rio de Janeiro, $H$. minor ocorre em simpatria com H. glazioviana, nos municípios de Nova Friburgo e Macaé, em torno de 850-1.100 m de altitude, em Floresta Ombrófila Densa montana, integradas na fitocória Centro Regional Sul do Brasil.

Material examinado: BRASIL: Rio DE JANEIRO: Macaé, 7-II-1985, C. Farney et al. 614 (F, RB); 18-II-1994, J.F.A. Baumgratz et al. 656 (FLOR, RB, SPF); II-1900, E.H.G. Ule 4555 p.p. (L); Nova Friburgo, 6-II-1888, A.F.M. Glaziou s.n. (F939768, R 9506).

8. Huberia nettoana Brade, Arq. Inst. Bio. Veg. 2(1): 13, est. 1, figs. 1-4. 1935. Lectótipo, aqui designado: BRASIL: São PAULO: Campos da Bocaina, 1879, L.S.M. Netto s.n. (R28859).

Nome vulgar: quaresma (Rio de Janeiro).

Huberia semiserrata é a espécie mais próxima de $H$. nettoana, principalmente pela semelhança das folhas, incluindo dimensões, forma, ápice, margem, indumento e presença de domácias, além do indumento glanduloso-ciliado nas inflorescências. Esta última característica é exclusiva desses dois táxons. Entretanto, $H$. nettoana distingue-se daquela espécie pela consistência papirácea e base curtamente decorrente ou agudo-decorrente da lâmina foliar, menor número de ramos $(2$, raro 6) nas inflorescências ou estes ausentes, pedicelo floral cilíndrico, hipanto 8-costado, não alado, menor comprimento dos estames $(9,2-16 \mathrm{~mm})$, anteras $(5,8-8 \mathrm{~mm})$ e seu tubo apical $(0,3-0,4 \mathrm{~mm})$ e estilete $(13,5-19,5 \mathrm{~mm})$ e pelo estigma capitado.

Distribui-se em Minas Gerais, Rio de Janeiro e São Paulo, na Serra da Mantiqueira, na Serra dos Órgãos e na Serra da Bocaina, e integrada na fitocória Centro Regional Sul do Brasil. Cresce em Floresta Ombrófila Densa montana e alto-montana, entre 1.400-1.700 m de altitude, em áreas de encosta ou relevo ondulado, formando pequenos agrupamentos na borda da mata ou contínua população ao longo de vertentes, além de áreas degradadas, como estradas, picadas ou clareiras. Pode rebrotar após o corte das árvores ou propagar-se por meio de sistema subterrâneo, possivelmente raízes gemíferas.

Material examinado: BRASIL: MinAs GeRAIS: Delfim Moreira, 7-VI-1950, M. Kuhlmann 2438 (SP); 28-I-1994, J.F.A. Baumgratz et al. 653, 653A, 653B (FLOR, RB, SPF). Rio DE JANEIRO: Itatiaia, 14-I-1936, C. Porto 2821 (RB); I-1939, L. Lanstyak 256 (MO, NY, RB, US); 31-I-1966, S. Andrade s.n. (Herbário Parque Nacional do Itatiaia 2144); 1-II-1965, E. Pereira 9819 (F, HB, K, M); I-1987, A. Salino 59 (SPF); 26-I-1994, J.F.A. Baumgratz et al. 651 (FLOR, RB, SPF); 26-I-1994, J.F.A. Baumgratz et al. 652, 652A 
(FLOR, RB, SPF); Nova Friburgo, I-1898, E.H.G. Ule 4555 p.p. (R); Teresópolis, 21-IV-1941, A.C. Brade 16792 (RB). São PAULO: Mun. indet., 11-II-1876, A.F.M. Glaziou 8375 p.p. (R); 15-30-I-1913, A. Lutz 356 (R); 14-V-1951, S. Vianna 3195 (NY, R); 26-IV-1951 (fr.), A.C. Brade 20739 (NY, RB).

9. Huberia ovalifolia DC., Prodr. 3: 167. 1828. Tipo: BRASIL: Espírito SANTo: Vila Nova de Almeida, 10-12 m, IV-1816, M.A.P. Wied-Neuwied s.n. (holótipo $\mathrm{G}$ n.v.; isótipo $\mathrm{BR} 2 \mathrm{x}$ ).

= Huberia resinosa Presl, Symb. Bot. 1(4): 58, tab. 37. 1832. Tipo: BRASIL, J.S. Presl 5 (holótipo PR n.v.).

Nomes vulgares: jacatirão (Espírito Santo e São Paulo); mangue-bravo, mangue-do-mato e quaresmabranca (Rio de Janeiro).

Por apresentarem as lacínias do cálice reduzidas em tamanho, $H$. consimilis, $H$. glazioviana e $H$. minor são as espécies mais próximas de $H$. ovalifolia, que se distingue pelas lacínias em forma de lobos oblatos, dorsalmente gibosos na região mediana, com ápice amplamente arredondado, e vascularizadas por 11-15 feixes primários. Daquelas espécies, $H$. consimilis é a mais afim, pela semelhança do hábito, ramos e folhas (vide comentários dessa espécie). O ápice das pétalas, geralmente arredondado ou obtuso-arredondado, às vezes obtuso-apiculado, arredondado-apiculado ou assimetricamente arredondado-agudo, também difere H. ovalifolia.

Distribui-se ao longo da costa brasileira, nos estados da Bahia, Minas Gerais, Espírito Santo, Rio de Janeiro e São Paulo. Encontrada em Floresta Ombrófila Densa, na Bahia, Espírito Santo, Rio de Janeiro e São Paulo, em formações de encosta ou matas nebulares, florestas de várzea, matas de galeria e restingas arbóreas ou arbustivas e áreas secundárias ou de pastagens. Quando em áreas abertas de matas de restinga, pode formar populações contínuas. Huberia ovalifolia integra duas fitocórias, Centro Regional da Costa Attântica e Centro Regional Sul do Brasil, além de se situar em dois centros de refúgios florestais pleistocênicos, "Bahia" e "RioEspírito Santo", ou centros de endemismos de espécies arbóreas de florestas pluviais de planícies (Prance 1982, 1989, 1994b).

Material examinado: BRASIL: BAHIA: Alcobaça, 11-V-1984, J.E.M. Brazão \& C.G. Oliveira 368 (HRB, RB); Canavieiras, 12-IV-1965, R.P. Belém \& M. Magalhães 811 (CEPEC, UB, US); 13-VII-1964, CMM 145 (CEPEC); 22-II-1970, J.A. Jesus 593 (CEPEC, RB); 13-VII-1964, N.T. Silva 58411 (NY,
UB, US); Caravelas, 29-III-1992, J.F.A. Baumgratz et al. 640 (RB, SPF); 18-I-1977, R.M. Harley 18081 (CEPEC, IPA, K, NY, U, UEC); 19-VI-1985, G. Hatschbach \& F.J. Zalma 49503 (CEPEC); 2-4-IX-1949, B. Lutz s.n. (R136678); Mucuri, 27-IV-1973, R.S. Pinheiro 2136 (CEPEC); 20-V-1980, L.A.M. Silva \& T.S. Santos 757 (ALCB, CEPEC, HRB); Porto Seguro, 9-II-1972, A. Eupunino 213 (CEPEC); 19-VII-1988, G. Hatschbach et al. 52252 (CEPEC); Prado, 10-II-1972, T.S. Santos 2234 (RB, US); 30-III-1989, L.A.M. Silva et al. 2658 (CEPEC, SP); Santa Cruz de Cabrália, 24-I-1972, A. Eupunino 176 (CEPEC); 21-II-1972, A. Eupunino 233 (CEPEC, US); Teixeira de Freitas, 18-VIII-1972, T.S. Santos 2350 (CEPEC, NY); Mun. indet., 15-I-1977, R.M. Harley et al. 17965 (K). Espírito SAnto: Conceição da Barra, 24-I-1992, O.J. Pereira et al. 3575 (VIES); Linhares, 29-V-1990, D.A. Folli 1136 (CVRD); 16-II-1981, I.A. Silva 237 (CEPEC, CVRD, SP, UEC); São Mateus, 29-III-1992, J.F.A. Baumgratz et al. 638, 639 (RB, SPF); 23-II-1965, A.P. Duarte 8866 (NY, RB). MinAs GeRAIS: sem localidade, 1845-46, J.F. Widgren s.n. (UPS); s.d., P. Claussen 2099 (G, L, MO, WU); s.d., H.R. s.n. (R167006). Rio DE JANEIRO: Angra dos Reis, 16-II-1984, D.S.D. Araújo 6115 (GUA, HRB); 23-VI-1993, D.S.D. Araújo 9841 (GUA); 10-IV-1991, D.S.D. Araújo \& R.R. Oliveira 9354 (GUA); 18-V-1971, L. Emygdio 3719(R); 30-IV-1992, C.A.L. Oliveira et al. 629 (GUA); Magé, 12-III-1903, P.K.M. Dusén 1946 (BM, GH, K, MG, R, S, US); XII-1897, E.H.G. Ule 4217 (HBG, R); VII-1895, E.H.G. Ule s.n. (HBG, R114913); I-1897, E.H.G. Ule s.n. (R114914); Niterói, 27-III-1826, W.J. Burchell 2889 (BM, GH, K); VII-1837, s.col. 755 (BM); VII-1839, s.col. 754 (K); Nova Friburgo, X-1842, P. Claussen 164 (BM, BR, G, K); Parati, XI-1994, J.F.A. Baumgratz et al. s.n. (RB397333); 22-III-1992, M.C. Marques et al. 293 (RB); 3-I-1981, L.A.F. Mathes 12091 (UEC); Petrópolis, II-1944, O.C. Góes \& Dionisio 90 (RB); Rio de Janeiro, 18-VIII-1977, D.S.D. Araújo 1842 (GUA); 1955, G.M. Barroso s.n. (RB92763); 18-IX-1991, J.F.A. Baumgratz \& C.A.L. Oliveira 619 (RB); 21-II-1992, J.F.A. Baumgratz et al. 629 (RB); 19-III-1935, A.C. Brade 14377 (RB); 20-VI-1961, A. Castellanos 23219 (G, GUA, IAN, SP, US); 15-XI-1945, A.P. Duarte s.n. (R45761); 15-I-1929, A. Ducke s.n. (NY, RB21540); 31-XII-1956, L. Emygdio 1106 (UC); 10-II-1975, L. Emygdio 1275 (R); III-1942, L. Emygdio \& E. Santos s.n. (R114862); 11-IV-1967, S. Ferreira 127 (GUA); 1867, A.F.M. Glaziou 97a (BR); 10-XII-1861, A.F.M. Glaziou 97b 
(R); 1867, A.F.M. Glaziou 574 (BR, K); 27-VI-1867, A.F.M. Glaziou 1271 (BR, F); 13-I-(10-XII?)-1872, A.F.M. Glaziou 5862 (BR, K, NY, P, R, S); 1889, A.F.M. Glaziou 17527 (BR, K, S); VI-1915, F.C. Hoehne 607 (SP); 8-I-1962, J.P. Lanna Sobrinho 122 (F, G, GH, GUA, IAN, K, SP, UC); 8-II-1966, J.P. Lanna Sobrinho 1623 (F, GUA, NY); 10-VI-1969, J.P. Lanna Sobrinho 1802 (BM, F, GUA, US); s.d., Lorenço s.n. (BR, K, M, RB111518, US2623410); VI-1833, B. Luschnath 10 (BR); 11-VII-1915, A. Lutz 786 (R); 1915, A. Lutz 825 (R); 24-III-1940, B. Lutz 1622 (R); II-1987, C. Magnanini 32 (R); 8-XII-1959, H.F. Martins 147 (GUA); 22-I-1960, H.F. Martins 150 (GUA); 1838, C.F.P. Martius 29 (G, GH, K, L, NY); 1-VII-1873, H. Mosén 11 (S); VII-1887, J. Moura 126 (BR); 15-V-1986, E.M. Occhioni 493 \& C.M. Rizzini 317 (RB, RFA); 3-VII-1984, C.A.L. Oliveira \& J. Caminote 43 (GUA); 3-I-1990, D.S. Pedrosa \& D. Sodré 1209 (GUA); 22-II-1942, E. Pereira 62 (F, MO, NY, RB, S); 11-VI-1953, E. Pereira 728 (RB); s.d., E. Pereira s.n. (R167010); 24-II-1959, E. Pereira \& A.P. Duarte 4507 (B, RB); 5-VI-1964, E. Pereira \& G. Pabst 8119 (PEL); 20-V-1958, E. Pereira et al. 3769 (RB); 17-VI-1958, E. Pereira et al. 3884 (RB); s.d., J.E. Pohl s.n. (BM); III-1818, J.E. Pohl 4156 \& H. Schott 5262 (F, GH, L, NY); II-1938, O. Reis s.n. (RB35805); III-1842, L. Riedel 164 (HBG); 18-VI-1872, J. Saldanha 961 (R); s.d., J. Saldanha 5041 (R); 15-I-1934, A.J. Sampaio \& O. Peckolt s.n. (R167017); 7-XII-1886, A. Schenck 1400 (BR); 21-I-1887, A. Schenck 2216 (BR); 1840, R.H. Schomburgk 72 (UPS); 1876, C.A.W. Schwacke 1189 (RB); 9-VI-1887, C.A.W. Schwacke 5611 (RB); s.d., C.A.W. Schwacke s.n. (R114864); 25-II-1886, C.A.W. Schwacke 5098 (RB); 1-II-1891, C.A.W. Schwacke 7179 p.p. (RB); 26-III-1967, H.E. Strang 1024 (HB, M, UC); 17-I-1944, M.H. Valle 8 (R); 1942, L. Tatto s.n. (RB76192); VII-1841, s.col. 5450 (BM); 26-XI-1891, s.col., s.n. (R167008); Mun. indet., 1814-17, J. Bowie \& A. Cunningham 121 (BM, NY); s.d., C.J.F. Bunbury s.n. (BR); s.d., F. Sellow 165 (US), 223 (BM); 1838-42, U.S. South Pacific Expl. Exped. Capt. Wilkes s.n. (GH, NY, US86157); Sem localidade, 1833, C. Gaudichaud 738 (G); s.d., C. Gaudichaud 739 (P); s.d., A.F.M. Glaziou 13835 (K); XII-1820, G.H. Langsdorff s.n. (F369359); XI-I-1831-32, L. Riedell s.n. (K); I-1832, L. Riedel \& B. Luschnatt 90 (GH, NY, S, US); s.d., J.C. Mikan s.n. (BR); 1841, A.F. Regnell 72 (S); 1815, F. Sellow s.n. (S); I-1916, D. Vincent s.n. (L); Herb. Regnelli 489, 1844, J.F. Widgren s.n. (S); 1844, J.F. Widgren s.n. (S, UPS); s.d., J.F. Widgren s.n. (S); 1886, s.col. (R). São PAULo: Caraguatatuba, 29-IV-1892, G. Edwall s.n. (SP11342); Ubatuba, 7(9?)-V-1988, R. Costa et al. 45 (HRCB, SP); 27-II-1964, N.D. Cruz 87 (K, NY, SP); 25-II-1971, M. Emmerich 3650 (R); 12-I-1991, F.C.P. Garcia et al. 597 (HRCB, SPSF); 29-III-1977, P.E. Gibbs et al. 4600A (MG, US); 23-V-1989, M. Kirizawa \& J.A. Correa 2185 (SP, SPSF); 30-VI-1959, M. Kuhlmann 4622 (SP); IV-1989, M.A. Rollo s.n. (SP232613); IV-1992, L.A. Skorupa \& Marta s.n. (RB397334, SPF); Mun. indet., 21-I-1971, L. Emygdio 3070 p.p. (R); Sem localidade, III-1979, M. Sazima 9919 (UEC). Sem Localidade ESPECIFICADA, Hooker-1835, 1829, M. Boaz 178 (K); s.d., M. Boaz s.n. (K); s.d., P. Claussen s.n. (BR 2x); s.d., J.B.A. Guilleminn 164 (G); s.d., J.E. Pohl s.n. (M); 3-?-1880, L. Riedel s.n. (K); s.d., L. Riedel s.n. (BR, L, M, MO3572880, S, UPS, WU); s.d., F. Sellow s.n. (BR, G, K, NY, P); s.d., D. Sucre 11080 (RB); s.d., s.col. 42 (BM); s.d., s.col. 1232 (NY); 223-Melast., s.d., s.col. (G); Ex Herb. H.W. Buek, s.d., s.col. (HBG).

10. Huberia parvifolia Cogn. in A. De Candolle \& C. De Candolle, Monogr. Phan. 7: 410. 1891. Lectótipo, aqui designado: BRASIL: RIO DE JANEIRO: 19-XII-1887 (1888), A.F.M. Glaziou 16817 (R); isolectótipos B n.v., BR, C, G, GH, K, L, P, R, W; fotos do isolectótipo B: F, $\mathrm{GH}, \mathrm{MO}, \mathrm{NY}$; foto do isolectótipo K: RB).

Pela margem foliar serrada ou serrulada para o ápice, presença de domácias e lacínias do cálice estreitamente triangulares, $H$. parvifolia é afim de $H$. triplinervis, diferenciando-se pela lâmina foliar com base aguda a agudo-cuneada, nervuras acródromas basais, menor comprimento do fruto (11-12 $\mathrm{mm})$ e do hipanto (3,9-4,3 $\mathrm{mm})$ e maior número (240-260) de sementes por fruto. Pela forma das lacínias do cálice, mostra também afinidade com as quatro espécies andinas, $H$. cogniauxii, $H$. peruviana, $H$. staminodia e $H$. weberbaueriana, distinguindo-se pelas folhas adultas com bainha esclerenquimática em torno dos feixes vasculares, inflorescências dos tipos metabotrióide e botrióide, maior comprimento do cálice (4,7-6,3 mm) e lacínias $(4-5 \mathrm{~mm})$ e menor comprimento do pedicelo floral (2-3,5 mm) e ovário (2,8-3,1 mm).

Endêmica do Rio de Janeiro e coletada apenas em Macaé de Cima, município de Nova Friburgo, em Floresta Ombrófila Densa montana, representando um padrão de distribuição do tipo micro-endemismo. É simpátrica com $H$. glazioviana, $H$. minor e $H$. triplinervis, e integrada na fitocória Centro Regional Sul do Brasil. 
Material examinado: BRASIL: RIo DE JANEIRO: Nova Friburgo, 28-I-1889, A.F.M. Glaziou 17528 (BR, C, G, K, P, R); s.d., A.F.M. Glaziou s.n., 16969 (R9510, sphalm H. triplinervia).

11. Huberia peruviana Cogn. in Martius \& Eichler, Fl. bras. 14(4): 10, tab. 1, fig. 2. 1886. Tipo: PERU: AMAzonas: habitat in montibus secus flumem Mayo prope Tarapoto, in m. Andára, Peruviae orientalis, VII-VIII-1856, R. Spruce 4828 (holótipo BR; isótipos BM, C, G, GH, K, LE n.v., NY, P, RB, US n.v., W; fotos do isótipo $\mathrm{K}$ : $\mathrm{F}, \mathrm{MO}, \mathrm{NY}, \mathrm{RB}$ ).

As folhas com a lâmina estreitamente ovada, às vezes elíptica, base obtusa, ápice agudo ou atenuadoagudo, margem $2 / 3$ superiores serrados e domácias peciolares diferenciam $H$. peruviana das demais espécies andinas, embora algumas dessas características sejam parcialmente comuns entre elas. Pela margem foliar serrada para o ápice, aproxima-se de $H$. semiserrata e $H$. nettoana. Porém, estas diferem de $H$. peruviana pelo tipo de domácia, hipanto alado e lacínias do cálice mais longas $(4,2-8,5 \mathrm{~mm})$, em $H$. semiserrata, e pelo hipanto costado e lacínias calicinais mais longas (3,2-9 mm), em H. nettoana, além dos respectivos locais de ocorrência.

Distribui-se ao sul do Equador e noroeste do Peru, em florestas baixo-montanas, entre $370-500 \mathrm{~m}$ de altitude e, geralmente, em florestas de altitude e matas nebulares, desde $1.200 \mathrm{~m}$ até $2.600 \mathrm{~m}$. No Peru, ocorre em florestas baixo-montanas e matas de altitude, incluindo áreas de transição entre esses dois tipos de vegetação. No Equador, é encontrada em manchas de florestas em ravinas, juntamente com fetos arborescentes, gramíneas, ervas e espécies arbustivas. Está integrada em duas fitocórias: Centro Regional Submontanhoso Andino Sul, abrangendo a área à noroeste do Peru, e Centro de Endemismo Arquipélago Montanhoso Andino Norte, na região ao sul do Equador.

Material examinado: EQUADOR: LoJA: $4 \mathrm{~km}$ south of Loja, 17-IV-1966, D.H. Knight 491 (US); NUDO DE Sabanilla, 8-II-1985, G. Harling \& L. Andersson 21810 (GB); 2-IV-1985, G. Harling \& L. Andersson 23541 (QCA, GB). PERU: SAN MARTIN: Jepelacio, X-1933, G. Klug 3271 (F, GH, K, MO, NY, S, US); Yambrasbamba: 1835, A. Mathews 1283 (K; foto RB).

12. Huberia piranii Baumgratz, Rodriguésia 50(76/77): 40, figs. 4-5. 2000 (1998). Tipo: BRASIL: Minas GeraIs: Diamantina, Serra do Espinhaço, 16-II-1973, G. Hatschbach \& Z. Ahumada 31637 (holótipo MBM; isótipos F, K, MO, NY, US).
Os exemplares de $H$. piranii eram identificados geralmente como $H$. laurina, provavelmente pelas lacínias do cálice estreitamente triangulares e margem foliar geralmente inteira, assim como por sua ocorrência em localidades de Minas Gerais. Apresenta, também, afinidades com $H$. carvalhoi e $H$. espiritosantensis (vide comentários dessas espécies). Huberia piranii distingue-se pelo indumento furfuráceo-glanduloso e viloso-glanduloso nas gemas vegetativas, regiões axilares adjacentes a estas, pecíolo e na face adaxial das folhas jovens, pela lâmina foliar papirácea, com base arredondada e ápice acuminado, às vezes, agudo, pétalas com ápice atenuado-acuminado a cuspidado, estames de dois tamanhos e menor comprimento das flores (20-36 mm), pedicelo floral (5,5-13,5 mm), frutos (17-25 mm) e sementes (2,2-5 mm), além da distribuição geográfica distinta.

Endêmica da região de Diamantina e cercanias, na Cadeia do Espinhaço, em Minas Gerais, a ca. $1.250 \mathrm{~m}$ de altitude. Ocorre em manchas de mata de galeria e em campos rupestres, nas encostas ou cumes de morros rochosos com arenito.

Material examinado: BRASIL: MinAs GeRAIS: Conselheiro Mata, 4-VI-1985, F. Barros 1091 (SP); Datas, 5-II-1972, W.R. Anderson et al. 35510 (MO, NY, UPS, US); Diamantina, 19-III-1970, H.S. Irwin et al. 27911 (F, GH, MO, NY, RB, US); 15-IV-1973, W.R. Anderson 8969 (F, MO, NY, R, UB, US); 14-III-1982, G. Hatschbach 44719 (MG, NY, US).

13. Huberia semiserrata DC., Prodr. 3: 167. 1828. Tipo: BRASIL: São PaUlo: in sylvis palustribus, s.d., C.F.P. Martius s.n. (holótipo M n.v.).

Nomes vulgares: oliveira-crespa, quaresma-branca, quaresmeira-branca-do-brejo, jacatirão, jacatirão-dogrande e jacatirão-do-brejo (São Paulo); jagüatirão-dobrejo (Paraná); cara-lanhada e carne-de-vaca (Santa Catarina); canela-do-brejo e jacatirão-de-brejo (sul do Brasil).

Huberia semiserrata destaca-se das demais espécies do gênero pelo hipanto e lacínias do cálice alados e pedicelo floral costado. Huberia nettoana é a espécie mais afim, pelo indumento também vilosoglanduloso das gemas vegetativas e regiões axilares adjacentes a estas, margem foliar serrulada ou serrada para o ápice, domácias laminares, hipanto nitidamente 8-costado e estames de dois tamanhos.

Distribui-se nos estados de São Paulo, Paraná, Santa Catarina e Rio Grande do Sul, desde o nível do mar até ca. $900 \mathrm{~m}$ de altitude, integrando duas fitocórias 
- Centro Regional Sul do Brasil e Região da Costa Atlântica ou Centro Regional das Matas Attânticas. Encontrada em Floresta Ombrófila Densa montana, em áreas antropizadas ao longo do litoral, nas vertentes ocidentais das Serras do Mar e Geral, restingas, formações secundárias de áreas brejosas, beiras de estradas, represas e rios, bordas de matas, campos, capoeiras e matas de restingas. Também medra em formações nebulares na Serra da Bocaina, em São Paulo, e em vegetação secundária do tipo pasto-sujo, alagada, onde pode constituir uma formação ou sinúsia de baixo estrato. Quando no interior da mata, integra o dossel da vegetação, sempre próxima à borda. Huberia semiserrata ocorre na província Atlântica de Cabrera \& Willink (apud Waechter 1985), que abrange também o litoral norte do Rio Grande do Sul e onde predomina vegetação silvática essencialmente tropical.

Material examinado: BRASIL: PARANÁ: Antonina, 13-XII-1967, G. Hatschbach 18104 (L); 5-I-1973, G. Hatschbach 31089 (NY, S, SP, UC); Guaratuba, 22-XI-1967, G. Hatschbach 17918 (F); 21-XI-1956, G. Hatschbach 3631 (NY); Paranaguá, 10-XI-1978, G. Hatschbach \& A. Kasper 41708 (B, HBG, NY, SPF, UB, UC, UEC); 1-XII-1983, G. Hatschbach \& R. Callejas 47180 (HRB, MG, UB); 9-XII-1911, P.K.M. Dusén 13501 (BM, F, GH, K, NY, S, US); 2-I-1967, G. Hatschbach 15608 (F, HB, K, NY); XII-1964, L.T. Dosbrowski 1117, Y. Saito 934 \& M.L. Pereira $375(\mathrm{GH})$. Santa Catarina: Florianópolis, 10-XII-1950, A.P. Duarte \& J.I. Falcão 3352 (MO, NY, RB); 17-XII-1969, R.M. Klein \& Bresolin 8506 (FLOR, ICN, US); 17-XII-1969, R.M. Klein \& Bresolin 8509 (FLOR, ICN, PACA); 8-II-1984, F.A. Silva f. 144 (FLOR); 4-XII-1985, M. Leonor Souza \& Amarildo 856 (FLOR, ICN, PACA); Itapema, 8-XII-1968, R.M. Klein 7998 (US); Palhoça, 22-XII-1952, R. Reitz 5040 (M, UC); 3-VIII-1985, D.B. Falkenberg \& C.R. Padovani 2545 (FLOR, HRB); São Francisco do Sul, XI-1883, E.H.G. Ule 99 (HBG); XII-1910, F.C. Hoehne 2381 (R); São João do Sul, 10-III-1984, D.B. Falkenberg 1396 (FLOR); Mun. indet., 19-XII-1957, R. Reitz \& R.M. Klein 5722 (B, BR, FLOR, G, HB, K, L, NY, UC); 1-I-1967, J.C. Lindemann \& J.H. Haas 3808 (K, NY, U, US). Rio GRANDE Do Sul: Torres, 20-XII-1980, J.L. Waechter 1798 (ICN, PEL); 23-V-1981, M. Leonor Souza s.n. (ICN51491). São Paulo: Cananéia, 5-XII-1985, H.F. Leitão Filho \& J.Y. Tamashiro 18037 (UEC); Rio Grande da Serra, 17-XII-1991, J.F.A. Baumgratz et al. 627 (RB, SP, SPF); 17-XII-1991, J.F.A. Baumgratz et al. 624, 625, 626 (RB, SP, SPF); 2-XII-1977, L.R.
Landrum 2760 (SP); 8-I-1987, M. Kirizawa \& M. Sugiyama 1812 (SP); Santo André, 8-II-1992, J.F.A. Baumgratz \& J.M. Mendonça 628 (RB, SPF); Santos, 27-XII-1966, J. Mattos 14399 (SP); 6-XII-1960, J. Mattos 8688 (SP); 1902, M. Wacket s.n. (WU); São Bernardo do Campo, 1902, A. Wachsmund s.n. (WU); 15-III-1992, J.F.A. Baumgratz 636 (RB, SPF); São José dos Campos, XII-1909, A. Löfgren 530 (RB, S); São Paulo, 14-XII-1917, F.C. Hoehne 1080 (BM, GH, RB, S, SP); 23-XI-1945, J.D. Vedove s.n. (SPF 82219); 2-XII-1941, W. Hoehne s.n. (SPF10936); 29-I-1942, W. Hoehne s.n. (SPF3691); 11-XII-1945, D.B.J. Pickel s.n. (SPSF2439, US1951743); 7-XII-1886, A. Usteri 35 (BR); 13-XII-1907, s.col. (SP); XII-1907, Lüdewaldt 85 (RB); 22-XII-1912, A.C. Brade 6055 (S); 1-XII-1932, F.C. Hoehne 24770 (BR, F, GH, NY, RB, SP); 12-III-1827, W.J. Burchell 4514 (GH, K, L, P); 16-III-1827, W.J. Burchell 4618 (K); VII-1901, R. Wettstein \& V. Schiffner 408 (WU); 23-XI-1913, A.C. Brade 6841 (SP); 26-XII-1933, S. Decker s.n. (SP31400); 14-I-1942, M. Viebig s.n. (SPSF1749); Chácara Flora, 4-XI-1966, B.C. Teixeira 146 (K, NY, SP, UEC); 10-XI-1953, M.A. Cunha s.n. (SPSF5146); s.d., S. Andrade 49 (R); 24-VII-1815, L. Riedel 275 (BM); 17-I-1827, W.J. Burchell 3871 (K, P); 23-XI-1966, O.P. Siqueira 20 (K, NY, SP, UEC); XII-1897, G. Edwall s.n. (SP11345); XII-1932, A.C. Brade 12297 (R, RB); 10-XII-1905, A. Usteri s.n. (SP11343); Mun. indet., 1-XI-1917, F.C. Hoehne s.n. (SP2999); XII-1917, A. Frazão s.n. (RB10782); 21-I-1971, L. Emygdio 3070 p.p. (R); 11-II-1876, A.F.M. Glaziou 8375 p.p. (R); X-1899, G. Edwall 99 (SP); II, s.col. (R); 9-II-1974, G.J.F. Pabst et al. 9573 (HB); 21-XII-1896, A. Löfgren s.n. (SP11347); s.d., F. Sellow 381 (WU); s.d., F. Sellow 1148, 1724, 5724 (F, US); Sem localidade, s.d., C. Gaudichaud 804 (R); s.d., Mendonça 29 (BR); s.d., F.S. Vianna 423 (R). SEM LOCALIDADE ESPECIFICADA: Herb. Reg. Berolinense, 1840, F. Sellow s.n. (K); 3-?-1880, L. Riedel s.n. (K); Ex Herb. hort. Petropolitani, s.d., L. Riedel s.n. (BR, GH, M, MO, NY, P, S, US86158); Herb. Reg. Berolinense, s.d., F. Sellow s.n. (BR, K, L); Acq. Journ. no. 2198, s.d., s.col. (WU); Herb. Lugd. Bat. 262, s.d., s.col. (L).

14. Huberia staminodia Baumgratz, Novon 9(2): 139, fig. 2. 1999. Tipo: PERU: AmAzonAs: Bongará, between río Utcubamba and Shipasbamba, $4 \mathrm{~km}$ from Campomiento Ingenio, altitude $1.520 \mathrm{~m}, 2-\mathrm{II}-1964$, P.C. Hutchinson \& J.K. Wright 3995 (holótipo NY; isótipos F, K, US, USM). 
Pela presença de domácias peciolares, flores também 5-meras e de estaminódios, $H$. staminodia distingue-se nitidamente das demais espécies do gênero, principalmente das mais afins - $H$. peruviana, $H$. weberbaueriana e $H$. cogniauxii.

Endêmica do noroeste do Peru, ocorre a ca. $1.520 \mathrm{~m}$ de altitude, em região montanhosa de baixa elevação no contexto andino, situada na Cordilheira Central ou Cordilheira Oriental (Weberbauer 1945), e próxima às áreas onde ocorre $H$. peruviana, incluindo aquelas ao sul do Equador. Huberia staminodia integra a região fitogeográfica denominada Ceja de la Montaña, na Ceja del Marañón, na parte superior das encostas e contrafortes, onde é comum a presença de neblina em todo o ano (Weberbauer 1945). Pouco freqüente na área, distribui-se de modo mais ou menos agrupado, sobre areia grossa e branca, em local desprovido de espécimes arbóreos. Integra também a região de floresta úmida das escarpas orientais de Young \& Léon (1993), do lado amazônico da Cordilheira Oriental Andina, e a fitocória Centro Regional Submontanhoso Andino Sul.

15. Huberia triplinervis Cogn. in A. De Candolle \& C. De Candolle, Monogr. Phan. 7: 410. 1891. Tipo: BRASIL: Rio DE JANEIRO: 13-V-1888, A.F.M. Glaziou 16969 (holótipo BR; isótipos B n.v., C, K, P, R, S; fotos do isótipo $\mathrm{B}$ : F, GH, MO, NY; foto do isótipo $\mathrm{K}: \mathrm{RB}$ ).

Ao descrever H. triplinervis, Cogniaux (1891) baseou-se na única coleção disponível, Glaziou 16969, cujos exemplares estão desprovidos de botões florais e flores. A morfologia seminal e o merisma floral foram os caracteres que o embasaram corretamente na inclusão da espécie nesse gênero. Huberia parvifolia é a espécie mais próxima de $H$. triplinervis, principalmente pela semelhança foliar e das inflorescências, distinguindo-se pelas folhas com nervuras acródromas suprabasais, base aguda ou obtusa e domácias sempre apiculadas, frutos maiores (12-18 $\times$ 4,3-5,5 mm), não costados, e menor número (190-210) de sementes.

É micro-endêmica e simpátrica com $H$. glazioviana, $H$. parvifolia e $H$. minor, em Macaé de Cima. H. triplinervis tem um padrão de distribuição geográfica do tipo micro-endêmico. Encontrada em Floresta Ombrófila Densa montana e, à semelhança do observado para aquelas três espécies, $H$. triplinervis integra a fitocória Centro Regional Sul do Brasil, reforçando a hipótese de que esta província florística corresponde a um centro regional de endemismo (Prance 1989, 1990, 1994a, b).
16. Huberia weberbaueriana Baumgratz, Novon 9(2): 140, fig. 3. 1999. Tipo: PERU: Amazonas: Bongará, below San Carlos, 1.700 m, VI-1915, A. Weberbauer 7145 (holótipo US; isótipos F, GH).

Huberia weberbaueriana é muito afim de H. cogniauxii, pela semelhança da morfologia foliar e tipo de domácia, distinguindo-se pelas nervuras últimas marginais foliares não confluentes suprabasalmente às nervuras acródromas laterais, pelo menor número de flores (11-19) e ramos da inflorescência (2-4), maior comprimento das flores $(24-30 \mathrm{~mm})$, maiores dimensões das peças florais e pelas tecas acentuadamente onduladas, além da área de ocorrência distinta, em altitudes mais baixas. Os frutos jovens são nitidamente maiores $(17-17,5 \mathrm{~mm})$ do que os frutos maduros de H. cogniauxii, inclusive do próprio pedicelo $(9-10 \mathrm{~mm})$.

Coletada no noroeste do Peru, um pouco mais ao norte das áreas onde ocorrem as três outras espécies extra-brasileiras, integrando as mesmas regiões fitogeográficas propostas por Weberbauer (1945) e por Prance $(1989,1990,1994 a, b)$. Pela altitude, $H$. weberbaueriana ocorre ou em encostas da mata pluvial da "montaña", limítrofe com a mata de Ceja, ou em mata nebular, sendo encontrada também em floresta úmida das escarpas orientais, com base em Young \& Léon (1993). É endêmica da região andina do Peru, em centro local de endemismo dentro da fitocória Centro Regional Submontanhoso Andino Sul.

Huberia distribui-se de modo disjunto na América do Sul, ocorrendo em dois centros - um na costa Atlântica e outro na costa Pacífica. A distribuição muito restrita de nove espécies do gênero, em ambos os centros, caracterizando endemismos pontuais, pressupõe que represente conquistas territoriais recentes na história biogeográfica do grupo.

$\mathrm{Na}$ caracterização morfológica das espécies, obtiveram-se novos dados através da análise anatômica de caracteres foliares e florais, alguns dos quais mostraram-se relevantes à taxonomia do grupo, como características da vascularização das folhas, hipanto, lacínias calicinais e pétalas e do anel vascular, na zona do disco. O gênero é estenopalinológico, ocorrendo pequenas variações quanto às características básicas dos grãos de pólen, mas que pouco auxiliam na identificação específica.

As numerosas esclereídes e/ou bainhas esclerenquimáticas em folhas, flores e/ou frutos podem representar uma adaptação das espécies às variações paleoambientais, possibilitando seu estabelecimento em locais mais abertos, inclusive nas áreas próximas ao nível do mar, como bordas de matas e restingas. 
As sementes aladas de Huberia parecem não se caracterizar como elementos dispersores a longa distância. Condições paleoambientais desfavoráveis durante períodos secos, o elevado número de embriões abortados e a distribuição muito restrita de algumas espécies representam indícios de dificuldades e dispersão limitada para o grupo. Ensaios de germinação com $H$. semiserrata evidenciaram a necessidade de alto teor de umidade para a emergência do embrião (Baumgratz, dados não publicados). Essa característica poderia explicar o não estabelecimento de Huberia em regiões mais centrais do continente sul-americano, onde as condições mais secas em tempos pretéritos provavelmente inibiram processos de germinação e/ou o estabelecimento de plântulas.

Agradecimentos - Ao Dr. José Rubens Pirani (USP), pela orientação no doutorado e constante incentivo; à Dra. Graziela Maciel Barroso (JBRJ, in memoriam), pelo incansável estímulo e ensinamentos; aos Drs. Vania Gonçalves-Esteves (Museu Nacional/UFRJ), Renato de Mello-Silva (USP), Maria Leonor D'El Rei Souza (UFSC), Nilda Marquete F. Silva (JBRJ) e Maria da Conceição Valente (JBRJ) e à Profa. Cláudia Barbieri Ferreira (Museu Nacional/UFRJ), pelas críticas, revisões e sugestões; ao Dr. John J. Wurdack (Smithsonian Institution, in memoriam), pelo constante e prestimoso atendimento, inclusive durante minha estadia na instituição; ao Dr. Dan Nicolson (Smithsonian Institution), pelos esclarecimentos sobre o Código de Nomenclatura Botânica; aos revisores anônimos e editores dessa revista, pela leitura do manuscrito e sugestões; ao CNPq, pelas bolsas de Doutorado e Produtividade em Pesquisa concedidas; às equipes dos Programas Diversidade Taxonômica e Mata Attântica (JBRJ), pelo apoio às expedições e disponibilidade de equipamentos; e ao Instituto de Pesquisas Jardim Botânico do Rio de Janeiro e Universidade de São Paulo, pelo apoio integral à realização do curso de doutoramento.

\section{Referências bibliográficas}

ANDRADE-LIMA, D. 1960. Estudos fitogeográficos de Pernambuco. Arquivos do Instituto de Pesquisas Agronômicas 5:305-342.

ANDRADE-LIMA, D. 1966. Esboço fitoecológico de alguns "brejos" de Pernambuco. Boletim Técnico do Instituto Agronômico 8:3-10.

ANDRADE-LIMA, D. 1970. Recursos vegetais de Pernambuco. Boletim Técnico do Instituto de Pesquisa Agronômica 41:1-32.

BARROSO, G.M., ANDREATA, R.H.P. \& LIMA, M.P.M. 1994. Morfologia de inflorescências. Universidade Santa Úrsula, Departamento de Biologia Vegetal, Rio de Janeiro.
BAUMGRATZ, J.F.A. 1985. Morfologia dos frutos e sementes de Melastomataceae brasileiras. Arquivos do Jardim Botânico do Rio de Janeiro 27:113-155.

BAUMGRATZ, J.F.A. 1999. Three new species of Huberia DC. (Melastomataceae) from Peru. Novon 9:139-146.

BAUMGRATZ, J.F.A. 2000a (1998). Duas novas espécies de Huberia DC. (Melastomataceae) para o Brasil. Rodriguésia 50:39-47.

BAUMGRATZ, J.F.A. 2000b. Two new species of Huberia (Melastomataceae: Merianieae) from Brazil. Brittonia 52:24-33.

BRADE, A.C. 1956. Melastomataceae novae IV. Arquivos do Jardim Botânico do Rio de Janeiro 14:213-228.

BRIGGS, B.G. \& JOHNSON, L.A.S. 1979. Evolution in the Myrtaceae - evidence from inflorescence structure. Proceedings of the Linnean Society of New South Wales 102:157-256.

CLAUSING, G. \& RENNER, S.S. 2001. Molecular phylogenetics of Melastomataceae and Memecylaceae: Implications for character evolution. American Journal of Botany 88:486-498.

COGNIAUX, A. 1886. Huberia. In Flora brasiliensis (C.F.P. Martius \& A.G. Eichler, eds.). F. Fleischer, Monachii, v.14, pars 4, p.7-10.

COGNIAUX, A. 1883-1888. Melastomataceae. In Flora brasiliensis (C.F.P. Martius \& A.G. Eichler, eds.). F. Fleischer, Monachii, v.14, pars 3-4.

COGNIAUX, A. 1891. Melastomaceae. In Monographiae Phanerogamarum (A. De Candolle \& C. De Candolle, eds.). G. Masson, Paris, v.7, p.1-1256.

CONTI, E., LITT, A. \& SYTSMA, K.J. 1996. Circumscription of Myrtales and their relationships to other rosids: evidence from rbcL sequence data. American Journal of Botany 83:221-233.

DE CANDOLLE, A.P. 1828. Melastomataceae. In Prodromus systematis naturalis regni vegetabilis (A.P. De Candolle, ed.). Treuttel et Wurtz, Paris, v.3, p.99-202.

GENTRY, A.H. 1992. Bignoniaceae - Part II (tribe Tecomeae). Flora Neotropica Monograph 25:1-370.

GENTRY, A.H. 1993. Overview of the Peruvian flora. In Catalogue of the flowering plants and gymnosperms of Peru (L. Brako \& J.L. Zarucchi, eds.). Missouri Botanical Garden, St. Louis, p.xxix-xxx.

GIULIETTI, A.M. \& PIRANI, J.R. 1988. Patterns of geographic distribution of some plant species from the Espinhaço range, Minas Gerais and Bahia, Brazil. In Proceedings of a Workshop on Neotropical distribution patterns (W.R. Heyer \& P.E. Vanzolini, eds.). Academia Brasileira de Ciências, Rio de Janeiro, p.39-69.

GIULIETTI, A.M., MENEZES, N.L., PIRANI, J.R., MEGURO, M. \& WANDERLEY, M.G.L. 1987. Flora da Serra do Cipó, Minas Gerais: caracterização e lista das espécies. Boletim de Botânica da Universidade de São Paulo 9:1-151.

HARRINGTON, H.D. \& DURRELL, L.W. 1957. Key to common leaf surface. In How to identify plants. The Swallow Press Inc., Chicago, p.58-59. 
HICKEY, L.J. 1979. A revised classification of the architecture of dicotyledonous leaves. In Anatomy of the dicotyledons (C.R. Metcalfe \& L. Chalk, eds.). Clarendon Press, Oxford, v.1, p.25-39.

HOLMGREN, P.K., HOLMGREN, N.H. \& BARNETT,L.C. 1990. Index Herbariorum. Part I: The Herbaria of the world. Regnum vegetabile. New York Botanical Garden, New York.

IBGE. 1992. Manual técnico da vegetação brasileira. Série Manuais Técnicos em Geociências, v.1. Instituto Brasileiro de Geografia e Estatística, Rio de Janeiro.

JOHANSEN, D. 1940. Plant microtechnique. McGraw-Hill, New York.

KLUCKING, E.P. 1989. Leaf venation patterns. Melastomataceae. J. Cramer, Gebrüder Borntraeger, Berlin, Stuttgart, v.4.

KRASSER, F. 1893. Melastomataceae. In Die natürlichen Pflanzenfamillien (A. Engler \& K. Prantl, eds.). Wilhelm Engelmann, Leipzig, v.3, p.130-199.

LAMAS, G. 1982. A preliminary zoogeographical division of Peru, based on butterfly distributions (Lepidoptera, Papilionoidea). In Biological diversification in the tropics (G.T. Prance, ed.). Columbia University Press, New York, p.336-357.

LYRA, A.L.R.T. 1984a. Efeito do relevo na vegetação de duas áreas do município do Brejo da Madre de Deus (PE). I Condições climáticas. In Anais do $34^{\circ}$ Congresso Nacional de Botânica (C.R. Dillenburg, coord.). Sociedade Botânica do Brasil, Porto Alegre, v.2, p.263-277.

LYRA, A.L.R.T. 1984b. Efeito do relevo na vegetação de duas áreas do município do Brejo da Madre de Deus (PE). II Estrutura da vegetação. In Anais do $34^{\circ}$ Congresso Nacional de Botânica (C.R. Dillenburg, coord.). Sociedade Botânica do Brasil, Porto Alegre, v.2, p.279-285.

LYRA, A.L.R.T. 1984c. Efeito do relevo na vegetação de duas áreas do município do Brejo da Madre de Deus (PE). III Diversidade florística. In Anais do $34^{\circ}$ Congresso Nacional de Botânica (C.R. Dillenburg, coord.). Sociedade Botânica do Brasil, Porto Alegre, v.2, p.287-296.

MARQUETE, N.F. 1979. Revisão taxonômica do gênero Barjonia Decne. (Asclepiadaceae). Rodriguésia 31:7-70.

MENTINK, H. \& BAAS, P. 1992. Leaf anatomy of the Melastomataceae, Memecylaceae, and Crypteroniaceae. Blumea 37:189-225.

PEREIRA, E. 1966. Flora da Guanabara V - Melastomataceae III (Final). Tribos Miconiea, Merianea, Bertoloniea, Microliceae. Rodriguésia 25:181-202.

PRANCE, G.T. 1982. Forest refuges: evidence from woody angiosperms. In Biological diversification in the tropics (G.T. Prance, ed.). Columbia University Press, New York, p.137-156.

PRANCE, G.T. 1989. American tropical forests. In Tropical rain forest ecosystems - biogeographical and ecological studies (H. Lieth \& M.J.A. Werger, eds.). Elsevier Science Publishers, Amsterdam, p.99-132.
PRANCE, G.T. 1990. As regiões fitogeográficas dos trópicos da América do Sul. In Anais do $35^{\circ}$ Congresso Nacional de Botânica (P.I. Braga et al., orgs. ). Sociedade Botânica do Brasil, Manaus, p.334-341.

PRANCE, G.T. 1994a. A comparison of the efficacy of higher taxa and species numbers in the assessment of biodiversity in the neotropics. Philosophical Transactions of the Royal Society of London, ser. B, 345:89-99.

PRANCE, G.T. 1994b. The use of phytogeographic data for conservation planning. In Systematics and conservation evaluation. Systematics Association (P.L. Forey, C.J. Humphries \& R.I. Vane-Wright, eds.). Clarendon Press, Oxford, v.50, p.145-163.

RADAMBRASIL. 1981. Levantamento de Recursos Naturais. Folha SD.24 Salvador. Ministério das Minas e Energia, Brasília, v.24.

RADFORD, A.E., DICKISON, W.C., MASSEY, J.R. \& BELL, C.R. 1974. Vascular plant systematics. Harper \& Row, New York.

RENNER, S.S. 1993. Phylogeny and classification of the Melastomataceae and Memecylaceae. Nordic Journal of Botany 13:519-540.

STACE, C.A. 1965. Cuticular studies as an aid to plant taxonomy. Bulletin of the British Museum (Natural History), Botany, ser. 4:1-79.

STRITTMATTER, C.G.D. 1973. Nueva tecnica de diafanizacion. Boletin de la Sociedad Argentina de Botanica 15:126-129.

TRIANA, J. 1865. Dispositivo Melastomacearum. Bulletin du Internationalle Congrès Botanique, Amsterdam, p.457-461.

TRIANA, J. 1871. Les Melastomacées. Transaction Linnean Society of London, Botany 28:1-188.

TROLL, W. 1964. Die Infloreszenzen. Gustav Fischer Verlag, Stuttgart, v.1.

TROLL, W. 1969. Die Infloreszenzen. Typologie und Stellung in Aufbau des Vegetationskorpers. Gustav Fischer Verlag, Stuttgart, v.2.

UPHOF, J.C. 1962. Plant hairs. Gebruder Borntraeger, Berlin.

WAECHTER, J.L. 1985. Aspectos ecológicos da vegetação de restinga no Rio Grande do Sul, Brasil. Comunicações do Museu de Ciências da Pontifícia Universidade Católica do Rio Grande do Sul, série Botânica 33:49-68.

WEBERBAUER, A. 1945. El mundo vegetal de los Andes peruanos. Talleres Graficos de la Editorial Lumen, Lima.

WURDACK, J.J. 1986. Atlas of hairs for Neotropical Melastomataceae. Smithsonian Contributions to Botany 63:1-80.

YOUNG, K.R. \& LÉON, B. 1993. Distribution and conservation of Peru's montane forests: interactions between the biota and human society. In Tropical montane cloud forests (L.S. Hamilton, J.O. Juvik \& F.N. Scatena, eds.). Procceding of the International Symposium. East-West Center, Puerto Rico, p.237-246. 